\title{
Characterization of electrospun poly(lactide) composites containing multiwalled carbon nanotubes
}

\author{
Ivan Ristic ${ }^{\prime 10}$, Aleksandra Miletic ${ }^{\prime 1}$, Nevena Vukic ${ }^{-1}$, \\ Milena Marinovic'-Cincovic ${ }^{2}$, Krisjanis Smits ${ }^{3}$, \\ Suzana Cakic ${ }^{\prime 4}$ and Branka Pilic ${ }^{\prime 1}$
}

\begin{abstract}
The main aim of this work was to obtain conductive polymer-based materials by incorporation of different amounts of multiwalled carbon nanotubes (MWCNTs) into poly(lactide)(PLA) using the electrospinning technique. Fiber-based nonwovens with $0.2,0.5,1$, and $3 \mathrm{wt} \%$ of MWCNTs were characterized regarding conductivity, morphology, thermal, and mechanical properties. It was confirmed that an increase of the MWCNTs content does not influence the increase of the material conductivity, since the conductivity was $170 \mathrm{ohm} \mathrm{sq}{ }^{1}$ for all composites. Scanning electron microscopy and transmission electron microscopy analyses revealed that smooth and beadless fibers were obtained, but also average diameters of composite nanofibers decreased with the increase of the MWCNTs content. Differential scanning calorimetry analysis showed that the presence of MWCNTs in the PLA matrix had a significant influence on the crystallization behavior of PLA nanofibers, because the decrease in crystallization temperature $\left(T_{c}\right)$ was detected. Also, the incorporation of MWCNTs into PLA fibers affected the melting process, enabling the generation of a form, while had no influence on ordered $\alpha$ crystal. The enthalpy of composite degradation decreased, because MWCNTs are well-known for good heat conductivity, and with that the second step of degradation slowed down, as it was confirmed by thermogravimetric analysis. The
\end{abstract}

\footnotetext{
${ }^{1}$ Faculty of Technology, University of Novi Sad, Novi Sad, Serbia

${ }^{2}$ Vinc ${ }^{2}$ Institute of Nuclear Sciences, University of Belgrade, Belgrade, Serbia

${ }^{3}$ Institute of Solid State Physics, University of Latvia, Riga, Latvia

${ }^{4}$ Faculty of Technology, University of Niš, Leskovac, Serbia

Corresponding author:

Ivan Ristic', Faculty of Technology, University of Novi Sad, Boulevard Cara Lazara 1, 21000 Novi Sad, Serbia. Email: ivan.ristic@uns.ac.rs
} 
addition of MWCNTs improved mechanical properties of composite fibers and caused the increase of both elasticity and tensile strengths of nanofibers.

\section{Keywords}

Poly(lactide) nanofibers, multiwalled carbon nanotubes, electrospinning, conductive polymer, thermal properties

\section{Introduction}

Hybrid polymer-based materials with tailored properties are under development in recent years. Enhanced thermal, mechanical, optical, electrical, and other properties of hybrid materials are the result of combining two or more phases in materials processing. Nowadays, the trend in the production of hybrid materials is the substitution of synthetic materials with biomaterials. The use of bio-based polymers gives added value to hybrid materials due to their biocompatibility, biodegradability, and easy processing. One of the most promising and often used bio-based polymers is poly(lactide) (PLA), which can be produced from sugar-based raw materials. ${ }^{1}$ PLA can be used for many applications, such as biomedical, pharmaceutical, or packaging, but, due to its good processability, also for some industrial applications, especially in the automotive industry. Even if PLA has some good properties, the main drawback is its brittleness, and because of that, it lacks in mechanical and thermal properties. ${ }^{2}$ Slow crystallization rate present in PLA limits wider use of this biomaterial. $^{2}$ These deficiencies can be overcome by adding some filler, macro or nano, into the PLA matrix. Many types of nanofillers were already used for improving PLA properties, such as silicon (IV)-oxide and titanium oxide nanoparticles, nanocellu-lose, different nanoclays, and carbon-based fillers. ${ }^{3-10}$ With the addition of fillers, besides improving mechanical and thermal properties, many scientists strive for obtaining conductive polymers. The main aim is to obtain light materials with mechanical and electrical properties similar to metals, but the main issue is to produce conductive polymer-based materials. As polymers are inert and used as insulators, it is necessary to incorporate conductive material into the matrix. Carbon-based materials like graphite, carbon black and recently nanoforms of these, graphene and carbon nanotubes (CNTs), are most commonly used conductive materials. ${ }^{11-13}$ Carbon nanofillers induce conductivity of composites when added to the polymer, even in a small amount, up to $5 \mathrm{wt} \%$. The main issue in the production of CNT-based nanocomposites is achieving homogenous disper-sion of CNTs into the polymer matrix. Many different methods, such as incorporation in situ, solvent dispersion, and melt mixing, were commonly used for dispersing of CNTs. Because of CNTs' poor solubility in organic solvents, it is hard to obtain a good dispersion, especially when higher concentrations of CNTs are used, and because of this, melt compounding is the most efficient method for the preparation of CNT-based polymer composites. During the last decade, electrospinning as a new method for the production of composite materials has been employed. ${ }^{14}$ The main principle of this technique is the use of high voltage as driving force for the production of nanofibers from polymer-based solutions. In this case, CNTs are dispersed not only by mechanical dispersion in solvent 
but also under the influence of the electric field. With more or less success, PLA/CNT nanofibers were produced by electrospinning and conductive polymer mats were obtained. ${ }^{15-17}$ CNTs in the PLA matrix do not only induce conductivity of polymer but also have an influence on the crystallization of PLA and separation of different forms of crystals thereby improving mechanical properties by increasing the PLA strength. The influence on the thermal stability of PLA/CNT composite materials is also observed. ${ }^{18,19}$

In this work, PLA-based composite nanofibers with different amounts of multiwalled carbon nanotubes (MWCNTs) were produced using the electrospinning technique in order to obtain conductive materials. Morphology of nanofibers and also electrical, mechanical, and thermal properties were examined and the impact of the amount of

MWCNTs on the obtained composites properties was tested.

\section{Experimental}

\section{Materials}

The PLA used in this study was provided by Esun, China. Parameters of the neat PLA are number-average molecular weight $\left(\mathrm{M}_{\mathrm{n}} \quad 1 / 4 \quad 60,520 \mathrm{~g} \mathrm{~mol}{ }^{1}\right)$, weight-average molecular weight $\left(\mathrm{M}_{\mathrm{W}}{ }^{1 / 4} 160,780 \mathrm{~g} \mathrm{~mol}^{1}\right)$, and polydispersity (Q 1/4 2.6; determined using gel permeation chromatography). PLA was dried $6 \mathrm{~h}$ at $50 \mathrm{C}$ prior to use.

MWCNTs with a diameter of $13 \mathrm{~nm}$, length of $1 \mathrm{~mm}$, and purity of $95 \%$ were supplied by a Bayer Material Science. Dichloromethane (DCM) (Fisher Scientific, Loughborough, UK) and dimethylformamide (DMF) (Centrohem, Stara Pazova, Serbia) were used as solvents without further purification.

\section{Preparation of solutions for electrospinning and obtaining of PLA-based nanofibers}

For experimental purpose, in this work, five different PLA-based fibers were prepared: one pure PLA nonwoven, which served as a control, and four composite PLA fibers containing $0.2,0.5,1$, and $3 \mathrm{wt} \%$ of MWCNTs, respectively. PLA solution was prepared by mixing appropriate amount of PLA in solvent mixture of DCM/DMF (in the ratio 6:5 v/v). Composite PLA solutions were prepared in a two-step mixing process: first pure PLA solution was prepared and then to this solution, a matching amount, which corre-sponds with a concentration of MWCNTs, was added (Table 1). This solution was treated in an ultrasonic bath for $20 \mathrm{~min}$ to ensure the dispersion of MWCNTs within the PLA matrix. After $24 \mathrm{~h}$ of mixing on a magnetic stirrer at room conditions, the solution was transferred to a plastic syringe which was connected to the system in the electro-spinning machine Fluidnatek LE-10 (Bioinicia, Paterna, Spain). Process parameters for electrospinning were adjusted for the preparation of each sample (Table 1).

\section{Characterization of nanofibers}

Morphology of obtained samples was analyzed using scanning electron microscopf (SEM), Lyra (Tescan, USA) operated at $25 \mathrm{kV}$. 
Table 1. Process parameters for PLA-based samples preparation by electrospinning.

\begin{tabular}{lcccccc}
\hline & $\begin{array}{c}\text { Solvent mixture } \\
\text { DCM/DMF }(\mathrm{g})\end{array}$ & $\begin{array}{c}\text { PLA } \\
(\mathrm{g})\end{array}$ & $\begin{array}{c}\text { MWCNTs } \\
(\mathrm{g})\end{array}$ & $\begin{array}{c}\text { Feed rate } \\
\left(\mu \mathrm{l} \mathrm{h}{ }^{1}\right)\end{array}$ & $\begin{array}{c}\text { Needle to } \\
\text { collector } \\
\text { distance }(\mathrm{cm})\end{array}$ & $\begin{array}{c}\text { Voltage } \\
(\mathrm{kV})\end{array}$ \\
\hline Pure PLA fibers & 12.7 & 2.24 & - & 2000 & 10 & 8 \\
PLA-0.2\% MWCNT & 12.7 & 2.242 & 0.00448 & 2500 & 10 & 8 \\
PLA-0.5\% MWCNT & 12.7 & 2.243 & 0.01121 & 2000 & 12 & 9 \\
PLA-1\% MWCNT & 12.7 & 2.245 & 0.02245 & 2500 & 15 & 9.5 \\
PLA-3\% MWCNT & 12.7 & 2.253 & 0.06759 & 2000 & 15 & 10.5 \\
\hline
\end{tabular}

PLA: poly(lactide); DCM: dichloromethane; DMF: dimethylformamide; MWCNTs: multiwalled carbon nanotubes.

Validation of the morphology nanofibers and verification of successful incorporation of MWCNTs into PLA-based nanofibers were confirmed using transmission electron microscopy (TEM; Tecnai G2 F20, FEI, USA). The samples for TEM imaging were placed on a holey carbon-coated grid AGS147-4 (Agar Scientific, Essex, UK).

The conductivity of nanofibers was explained by measuring sheet resistivity of samples. $^{20}$ The sheet resistivity of PLA/MWCNT nanocomposites was taken on four-point probe device and was measured at five different places on the surface of the samples, and the average values were taken. All measurements were done at room temperature.

Dielectric properties (conductance) of the samples were measured by Digital LCR Meter 4284A, in the frequency range from $20 \mathrm{~Hz}$ to $1 \mathrm{MHz}$ at the room temperature.

Differential scanning calorimetry (DSC) measurements were performed using a Setaram 151 R instrument (software SETSOFT 2000 from Setaram) in the temperature range from $25 \mathrm{C}$ to $200 \mathrm{C}$ under nitrogen atmosphere at a heating rate of $5 \mathrm{C} \mathrm{min}{ }^{1}$.

Cold crystallization degree $\left(\mathrm{X}_{\mathrm{cc}}\right)$ was estimated according to the following equation:

$$
X_{\mathrm{cc}}(\%)=\frac{\Delta H_{m}-\Delta H_{\mathrm{c}}}{\Delta H_{\mathrm{m}}^{0} \times \mathrm{wt}_{\mathrm{PLA}}} \times 100
$$

where $\mathrm{DH}_{\mathrm{m}}$ refers to the enthalpy of melting, $\mathrm{DH}_{\mathrm{c}}$ refers to the cold crystallization enthalpy of PLA/CNT composites; $\mathrm{DH}_{\mathrm{m}}{ }^{0}$ refers to the enthalpy value of $100 \%$ crystalline PLA, which is $93 \mathrm{~J} \mathrm{~g}^{1}$ and wtPLA refers to the weight ratio of PLA in PLA/CNT composites. 21

Thermogravimetric analysis (TGA) was performed on the Setaram Setsys Evolution-1750 instrument. Samples (average weight $5 \mathrm{mg}$ ) were heated from $30 \mathrm{C}$ to $500 \mathrm{C}$ at the heating rate of $10 \mathrm{C} \min ^{1}$ in an argon atmosphere with the gas flow rate of $20 \mathrm{~cm}^{3} \mathrm{~min}^{1}$. During the heating period, the weight loss and temperature difference were recorded as a function of temperature.

Mechanical properties of electrospun nonwovens were determined using an Instron 1122 tensile testing machine (UK), with a crosshead speed of $1 \mathrm{~mm} \mathrm{~min}^{1}$ at room conditions. Samples were cut from prepared nonwoven mats in the form of a rectangle, with approximate dimensions $1050 \mathrm{~mm}^{2}$. 


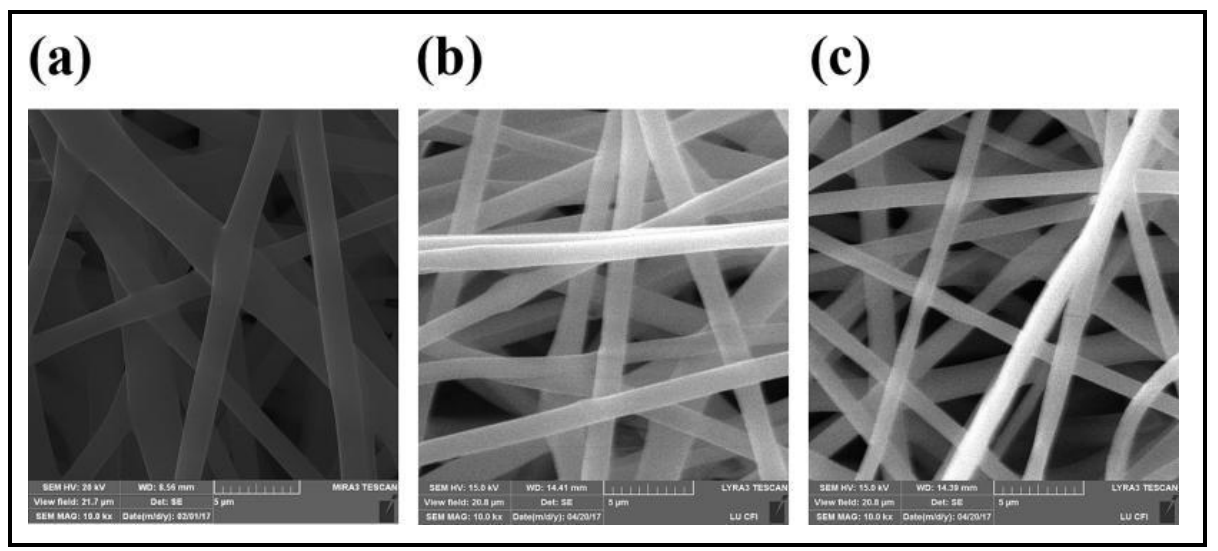

Figure 1. SEM micrographs of (a) pure PLA fibers and (b) composite fibers with 0.5 wt\% of MWCNTs, and (c) 3 wt\% of MWCNTs.

SEM: scanning electron microscopf; PLA: poly(lactide); MWCNTs: multiwalled carbon nanotubes.

\section{Results and discussion}

SEM images of pure and MWCNT-loaded PLA-based nanofibers are shown in Figure 1, where pure PLA nanofibers are shown in Figure 1(a). It can be seen that smooth and uniform fibers without beads and drops were obtained using appropriate process parameters. The addition of nanofiller did not disrupt the morphology of nanofibers; smooth and beadless fibers were obtained from all prepared PLA-based solutions containing MWCNTs (Figure 1(b) and (c)). Due to the higher conductivity of composite polymer solutions caused by the presence of MWCNTs, the elongation of the viscoelastic solution in high-voltage electric field increased, ${ }^{22}$ so with the higher amounts of filler, fibers with lower diameters were obtained (Table 2).

In the electric field, MWCNTs orient in the direction of the electric field, so they are distributed along the nanofibers. ${ }^{15}$ Due to good dispersion of MWCNTs within PLA, they are encapsulated into fibers, and it was not possible to notice them using SEM microscope. TEM results revealed the presence of by-products (carbon-type materials) of MWCNTs into the fibers, which is shown in Figure 2(b). Even the best quality MWCNTs have some carbon by-products and if these by-products are successfully incorporated into the nanofibers, this ensures that MWCNTs are also incorporated into the polymer matrix. Within nanofibers with a lower amount of MWCNTs $(0.2 \mathrm{wt} \%$ and $0.5 \mathrm{wt} \%)$, nanotubes existed as single tubes, randomly dispersed through the fiber volume, because concentration was too low and no strong forces between them were present (Figure 2(c)). With the increase of the MWCNTs' amount, attraction forces between MWCNTs are becoming stronger and they start to form aggregates (Figure 2(d)). Even though aggregates of MWCNTs are present, this did not hinder the conductivity of the fibers.

For all composite fibers, sheet resistivity was around $170 \mathrm{ohm} \mathrm{sq}{ }^{1}$, so once the conductivity percolation was achieved, the increase in the MWCNTs' amount had no 
Table 2. Average diameters of obtained PLA-based nanocomposite fibers.

\begin{tabular}{lcc}
\hline Sample & Average diameter $(\mu \mathrm{m})$ & Standard deviation \\
\hline Pure PLA fibers & 1.65 & 0.5 \\
PLA-0.2\% MWCNT & 1.53 & 0.46 \\
PLA-0.5\% MWCNT & 1.28 & 0.16 \\
PLA-1\% MWCNT & 1.16 & 0.38 \\
PLA-3\% MWCNT & 0.87 & 0.6 \\
\hline
\end{tabular}

PLA: poly(lactide); MWCNT: multiwalled carbon nanotube.

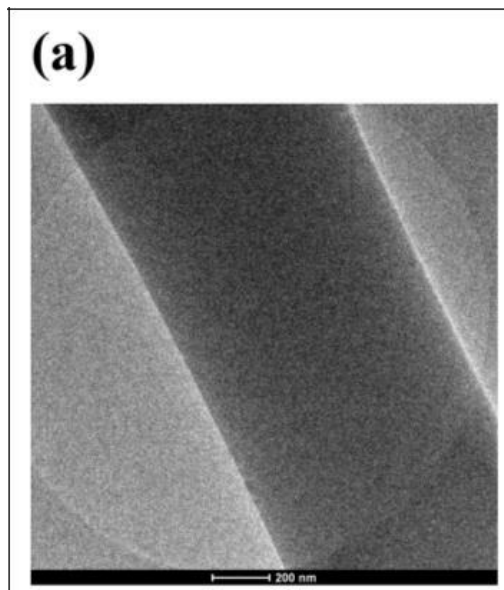

(c)

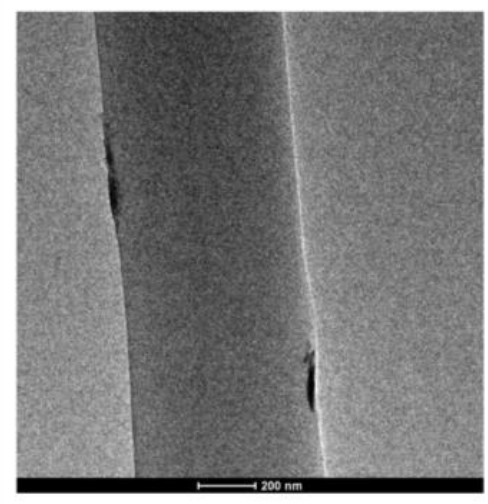

\section{(b)}

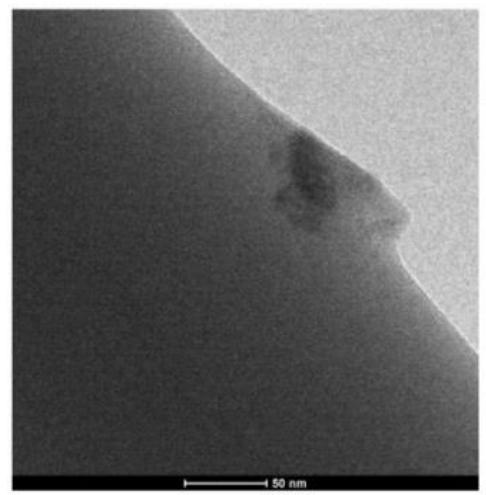

(d)

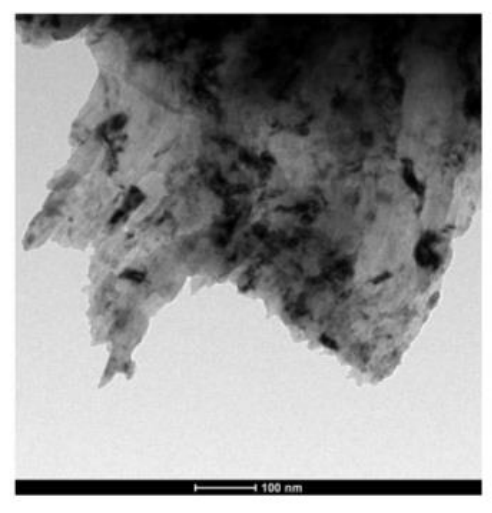

Figure 2. TEM micrographs of (a) pure PLA fibers and (b) composite fibers with 0.5 wt \% of MWCNTs and (c) and (d) 3 wt\% of MWCNTs.

TEM: transmission electron microscope; PLA: poly(lactide); MWCNTs: multiwalled carbon nanotubes. 


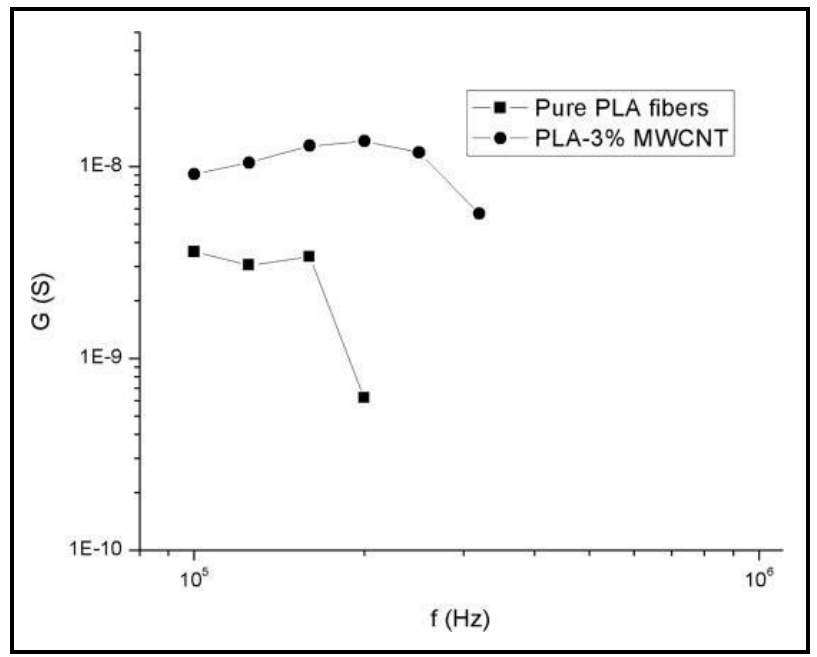

Figure 3. Conductance of pure PLA fibers (\&) and composite fibers with 3 wt\% of MWCNTs ( ). PLA: poly(lactide); MWCNTs: multiwalled carbon nanotubes.

effect on the conductivity of the fibers. In our experiment, the lowest concentration of CNTs was $0.2 \mathrm{wt} \%$, and even this small amount of carbon filler is sufficient for obtaining conductive material. SEM images illustrated that MWCNTs are not connected to each other along the fibers, but they are randomly arranged. Conductivity, in this case, is achieved with specific morphology of samples, where fibers form an unregular three-dimensional network which is enhancing the formation of percolation network. ${ }^{23,24}$ As the fiber diameter is small and the fibers are thin, MWCNTs in two connected fibers interact and transfer conductivity further along with the network. With the increasing MWCNTs content, conductivity was not changed, because the fiber network forms the same number of active places that take part in electron transfer.

It was shown that specific morphology achieved using the electrospinning technique enables the preparation of conductive materials with the addition of very low concentrations of MWCNTs, which is hard to achieve with conventional process techniques. It can be explained by the fact that MWCNTs are embedded in polymer fibers, and because of this, when the conductive threshold was achieved, further addition of MWCNTs had no influence on the value of conductance. This was confirmed by con-ductance measurement on the frequency range from $100 \mathrm{kHz}$ to $1 \mathrm{MHz}$ (Figure 3). MWCNTs had a strong influence on the ionic and dipole interaction in the PLA matrix, increasing conductance and shifting this transition to the higher frequency.

The results of DSC analysis of obtained nanofibers are summarized in Table 3 and Figure 4. It is evident that the presence of CNTs in the PLA matrix had a significant influence on the crystallization behavior of PLA nanofibers, because decreasing of crystallization temperature $\left(\mathrm{T}_{\mathrm{c}}\right)$ was detected. As referenced in the literature, MWCNTs 
Table 3. Thermal properties of PLA-based composite nanofibers.

\begin{tabular}{llccc}
\hline Sample & $\mathrm{T}_{\mathrm{c}}\left({ }^{\circ} \mathrm{C}\right)$ & $\mathrm{T}_{\mathrm{m} 1}\left({ }^{\circ} \mathrm{C}\right)$ & $\mathrm{T}_{\mathrm{m} 2}\left({ }^{\circ} \mathrm{C}\right)$ & $\mathrm{X}_{\mathrm{cc}}(\%)$ \\
\hline Pure PLA fibers & 128.83 & 155.8 & 160.8 & 24.69 \\
PLA-0.2\% MWCNT & 110.8 & 151 & 160.1 & 32.17 \\
PLA-0.5\% MWCNT & 116.4 & 151.8 & 159.7 & 27.14 \\
PLA-1\% MWCNT & 109.24 & 150.5 & 160 & 17.84 \\
PLA-3\% MWCNT & 114.54 & 152.1 & 160.6 & 31.20 \\
\hline
\end{tabular}

PLA: poly(lactide); MWCNT: multiwalled carbon nanotube; $\mathrm{T}_{\mathrm{c}}$ : crystalline temperature; $\mathrm{Tm}_{\mathrm{m}}$ : melting temperature; $\mathrm{X}_{\mathrm{Cc}}$ : degree of crystallinity.

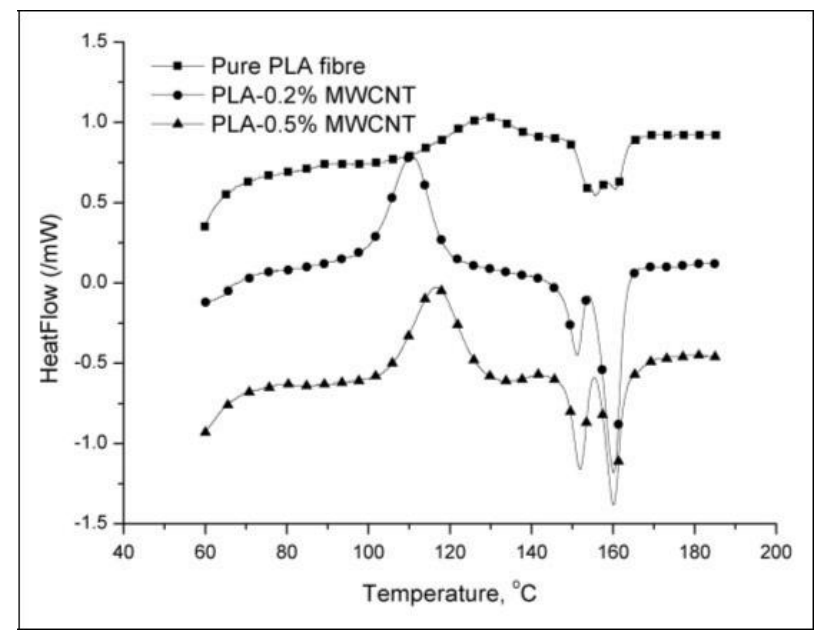

Figure 4. DSC thermograms of pure PLA fibers and composite fibers with $0.2 \mathrm{wt} \%$ and 0.5 wt $\%$ of MWCNTs.

DSC: differential scanning calorimetry; PLA: poly(lactide); MWCNTs: multiwalled carbon nanotubes.

can serve as nucleating agents and they ease crystallization of PLA. ${ }^{18}$ The highest decrease of $\mathrm{T}_{\mathrm{c}}$ occurred with the addition of $1 \mathrm{wt} \%$ of MWCNTs amounted for almost

$20{ }^{\circ} \mathrm{C}$. With the decrease of $\mathrm{T}_{\mathrm{c}}$, separation of different crystal forms in PLA was more prominent, so two different melting points were detected on DSC graphs. The first melting point decreased with the addition of MWCNTs for $3-4{ }^{\circ} \mathrm{C}$, which is the con-

sequence of ease crystallization, but the second melting point remained the same. Considering two crystal forms of PLA, $\alpha$ i $\alpha^{\prime}$, this kind of behavior was expected, related to the fact that MWCNTs can act as a nucleating agent. Namely, PLA belongs to the

group of semicrystal polymers and dominant form of crystals present in the PLA matrix is a form. The melting temperature of these crystals is related to the ratio of L-lactide as well as to the presence of filler. The addition of MWCNTs definitely leads to an increase 


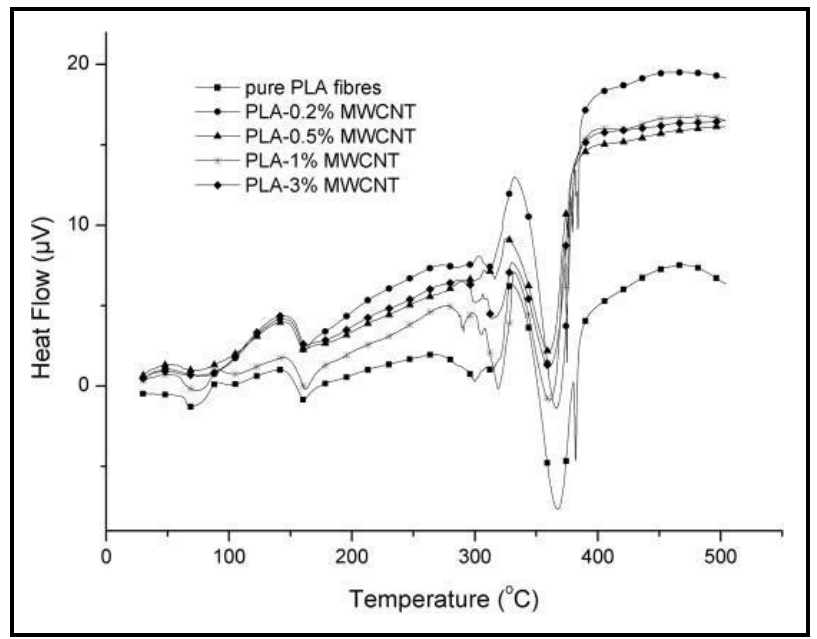

Figure 5. DTA curves of obtained composite nanofibers.

DTA: differential thermal analysis.

in PLA crystallinity rate through the increase in enthalpy of melting of a crystals. However, because of irregularity and the shape of the nucleating agent, less ordered $\alpha$ ' form crystal has been formed, which is proved with melting peak that occurred at a lower melting temperature compared to a form. The addition of MWCNTs to PLA fibers enables $\alpha$ ' form formation, while has no influence on ordered a crystal. Because of this, with increasing of MWCNTs' loading, decreasing of $\mathrm{T}_{\mathrm{m} 1}$ (derived from $\alpha$ ' form) is detected, which is a consequence of increasing the number of nucleating places that further eases the crystallization. This causes a slight increase in the crystallinity of PLA fibers, because the overall enthalpy of melting, which presents the sum of enthalpies of melting of a and $\alpha^{\prime}$ crystals, increased (Table 3).

Comparison of thermal properties of pure PLA and PLA-based composite fibers is shown in Figure 4, where the influence of the presence of MWCNTs in the PLA matrix can be clearly noticed. Crystallization and melting peaks are sharper and separation of different forms of crystals is more evident within a sample with $0.2 \mathrm{wt} \%$ of MWCNTs.

Thermal stability of the obtained nanofibers was examined using the TGA method. It was shown that the overall stability of the samples was not affected by the presence and the amount of MWCNTs (Figure 5). Pure PLA and the PLA composite with the $0.2 \mathrm{wt} \%$ of MWCNTs had slightly delayed degradation for a few degree Celsius, but that was not a significant difference in thermal stability. Considering SEM and TEM micrographs, it was proved that MWCNTs were present inside the polymer fibers, so an increase of thermal stability was not expected, because the degradation process starts from the surface of the fibers, on which the filler particles, that are inside, did not have any influence. In other words, a filler that was inside the fibers did not have influence on heat flow and fiber degradation process itself. However, when differential thermal analysis 
Table 4. Mechanical properties of PLA-based nanofibers.

\begin{tabular}{llc}
\hline Sample & $\varepsilon(\%)$ & $\sigma(\mathrm{MPa})$ \\
\hline Pure PLA fibers & 14 & 0.43 \\
PLA-0.2\% MWCNT & 14.4 & 0.64 \\
PLA-0.5\% MWCNT & 15 & 1 \\
PLA-1\% MWCNT & 20 & 1.74 \\
PLA-3\% MWCNT & 22 & 1.92 \\
\hline
\end{tabular}

PLA: poly(lactide); MWCNT: multiwalled carbon nanotube.

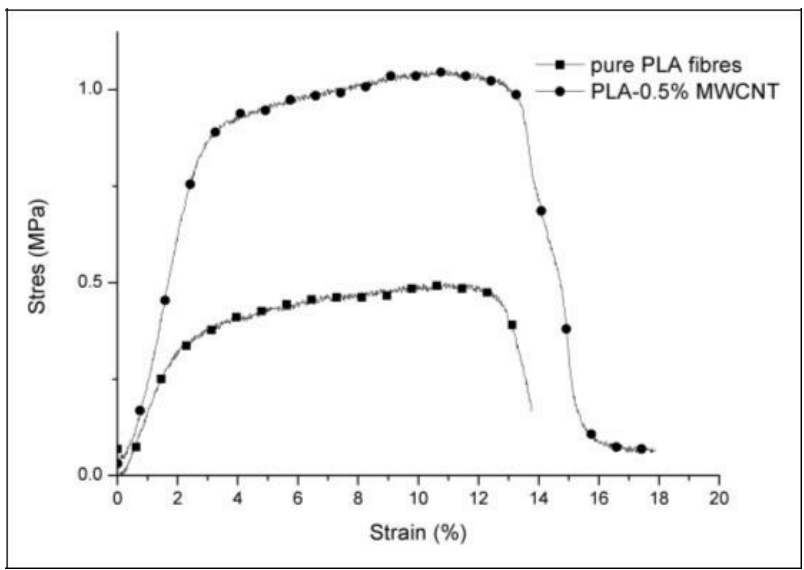

Figure 6. Mechanical properties of pure PLA fibers and PLA composite fibers. PLA: poly(lactide).

curves of pure PLA and composite fibers were compared, no influence of the filler on thermal stability was observed (Figure 4).

Values of mechanical properties, elongation at break $(\varepsilon, \%)$, and tensile strength $(\sigma$, $\mathrm{MPa}$ ) are summarized in Table 4. The addition of MWCNTs caused the increase of both elasticity and tensile strengths of nanofibers (Figure 6). It was noticed that the presence of MWCNTs had a higher influence on tensile strength, increasing it up to five times, which was expected due to tensile properties of CNTs themselves. The increase rate of elongation was lower, but significant when compared pure PLA and PLA-based composite with $3 \mathrm{wt} \%$ of MWCNTs.

\section{Conclusions}

This article illustrates that the electrospinning technique enables the production of conductive fibers made of biobased and biodegradable polymers with the addition of small amounts of MWCNTs, where specific morphology plays a significant role in transferring of conductivity. In this research, it was shown that MWCNTs are 
successfully incorporated into the PLA matrix and that uniform, smooth, and beadless fibers were obtained. The decrease of the average diameter with the increased amount of MWCNTs was observed, due to higher conductivity of polymer solution. Applied technique allowed good dispersion of MWCNTs into the PLA matrix and enabled their orientation in the direction of the fibers. The addition of MWCNTs increased crystallization rate of composite nanofibers, eased formation of $a^{0}$ crystal form and lowered melting temperature compared to pure PLA fibers. Thermal stability of the fibers was increased with the addition of MWCNTs, through slowing down of second degradation step. With the addition of nanofiller, elasticity and tensile strength of fibers increased, together with the toughness of the samples. Materials obtained this way are conductive, mechanically persistent, and thermally stable, which open brand new possibilities of their applications.

\section{Funding}

The author(s) disclosed receipt of the following financial support for the research, authorship, and/or publication of this article: The authors would like to thank the Ministry of Education, Science and Technological Development, Republic of Serbia, for funding projects III45022 and 172056 and European Cooperation in Science and Technology (COST) action CA15107.

\section{ORCID iD}

Ivan Ristic' (D https://orcid.org/0000-0002-4470-4929

\section{References}

1. Nampoothiri KM, Nair NR and John RP. An overview of the recent developments in polylactide (PLA) research. Bioresource Technol 2010;101:8493-8501.

2. Raquez JM, Habibi Y, Murariu M, et al. Polylactide (PLA)-based nanocomposites. Prog Polym Sci 2013;38:1504-1542.

3. Pilic B, Radusin T, Ristic I, et al. Hydrophobic silica nanoparticles as reinforcing filler for poly (lactic acid) polymer matrix. HemInd 2016;70:73-80.

4. Fonseca $\mathrm{C}$, Ochoa A, Ulloa MT, et al. Poly(lactic acid)/TiO2 nanocomposites as alternative biocidal and antifungal materials. Mater Sci Eng C 2015;57:314-320.

5. Xu CJ, Lv QL, Wu DF, et al. Polylactide/cellulose nanocrystal composites: a comparative study on cold and melt crystallization. Cellulose 2017;24:2163-2175.

6. Martı'nez-Sanz M, Lopez-Rubio A and Lagaron JM. Dispersing Bacterial Cellulose Nanowhiskers in Polylactides via Electrohydrodynamic Processing. J Polym Environ 2014;22: $27-40$.

7. Rhim JW, Hong SI and Ha CS. Tensile, water vapor barrier and antimicrobial properties of PLA/nanoclay composite films. LWT - Food Sci Technol 2009;42:612-617.

8. Busolo MA, Fernandez P, Ocio MJ, et al. Novel silver-based nanoclay as an antimicrobial in polylactic acid food packaging coatings. Food Addit Contam A 2010;27:1617-1626.

9. Zhou Q and Xanthos M. Nanoclay and crystallinity effects on the hydrolytic degradation of polylactides. Polym Degrad Stabil 2008;93:1450-1459.

10. Goncalves C, Goncalves IC, Magalhaes FD, et al. Poly(lactic acid) Composites Containing Carbon-Based Nanomaterials: A Review. Polymers-Basel 2017;9:269-306. 
11. Stankovich S, Dikin DA, Dommett GH, et al. Graphene-based composite materials. Nature 2006;442:282-286.

12. Thostenson ET and Chou TW. Aligned multi-walled carbon nanotube-reinforced composites: processing and mechanical characterization. J Phys D 2002;35: L77-L80.

13. Wu DF, Wu LA, Zhou WD, et al. Crystallization and biodegradation of polylactide/carbon nanotube composites. Polym Eng Sci 2010;50:1721-1733.

14. Sullivan EM, Karimineghlani P, Naraghi M, et al. The effect of nanofiller geometry and compounding method on polylactic acid nanocomposite films. EurPolym J 2016;77:31-42.

15. Yang T, Wu DF, Lu LL, et al. Electrospinning of polylactide and its composites with carbon nanotubes. Polym Composite 2011;32:1280-1288.

16. Magiera A, Markowski J, Menaszek E, et al. PLA-Based Hybrid and Composite Electrospun Fibrous Scaffolds as Potential Materials for Tissue Engineering. J Nanomater 2017:1-11.

17. McCullen SD, Stano KL, Stevens DR, et al. Development, optimization, and characterization of electrospun poly(lactic acid) nanofibers containing multi-walled carbon nanotubes. J Appl Polym Sci 2007;105:1668-1678.

18. Park SH, Lee SG and Kim SH. Isothermal crystallization behavior and mechanical properties of polylactide/carbon nanotube nanocomposites. Compos A 2013;46:11-18.

19. Barrau S, Vanmansart C, Moreau M, et al. Crystallization Behavior of Carbon Nanotu-be Polylactide Nanocomposites. Macromolecules 2011;44:6496-6502.

20. Blythe AR. Electrical resistivity measurements of polymer materials. Polym Test 1984;4: 195-209.

21. Ke T and Sun X. Effects of moisture content and heat treatment on the physical properties of starch and poly(lactic acid) blends. J Appl Polym Sci 2001;81:3069-3082.

22. Angammana CJ and Jayaram SH. Analysis of the Effects of Solution Conductivity on Electrospinning Process and Fiber Morphology. IEEE T Ind Appl 2011;47:1109-1117.

23. Dror Y, Salalha W, Khalfin RL, et al. Carbon Nanotubes Embedded in Oriented Polymer Nanofibers by Electrospinning. Langmuir 2003;19:7012-7020.

24. Wang SH, Wan Y, Sun B, et al. Mechanical and electrical properties of electrospun PVDF/ MWCNT ultrafine fibers using rotating collector. Nano Res Lett 2014;9:522. 